\title{
Reducing Major Rule Violations in Commuter Rail Operations: The Role of Distraction and Attentional Errors
}

\author{
Raja Parasuraman, George Mason University \\ George Elsmore, Veolia TransDev Inc. \\ Matthew Isaac, Volpe National Transportation System Center \\ Donald L. Fisher, University of Massachusetts, Amherst
}

\begin{abstract}
Recent accidents in commuter rail operations and analyses of rule violations have highlighted the need for better understanding of the contributory role of distraction and attentional errors. Distracted driving has thoroughly been studied in recent years, but distraction during rail operations has been less extensively examined. This Discussion Panel involves four speakers who will examine different aspects of the distraction issue. Topics will include a systems analysis of rail operations, analysis of rule violations and surveys of locomotive engineers, description of a high-fidelity rail simulator, and results from a two-part study using this simulator to examine distraction and attentional errors in commuter rail operations. Implications of the findings for reducing major rule violations and improving the safety of rail operations will be discussed.
\end{abstract}

\section{INTRODUCTION}

One of the major rule violations in passenger rail operations that a locomotive engineer can make is failing to stop at a red signal. Not complying with a speed restriction represents another violation. The potential consequence of such violations can be staggering: Should a red signal violation leads to a collision, it can mean the loss of many lives and injuries, a major chemical spill, or substantial equipment damage. A number of engineering controls and operating rules have been implemented to prevent these types of human factor related errors. For instance, railway signal systems are complex integrated systems designed to be failsafe, and engineers and conductors are required to verbally acknowledge signal indications, speed restrictions and other key operating directives with one another via radio communication. Surprisingly though, and despite strict operating rules and ongoing training, red signal and other serious rule violations continue to occur (see Figure 1).

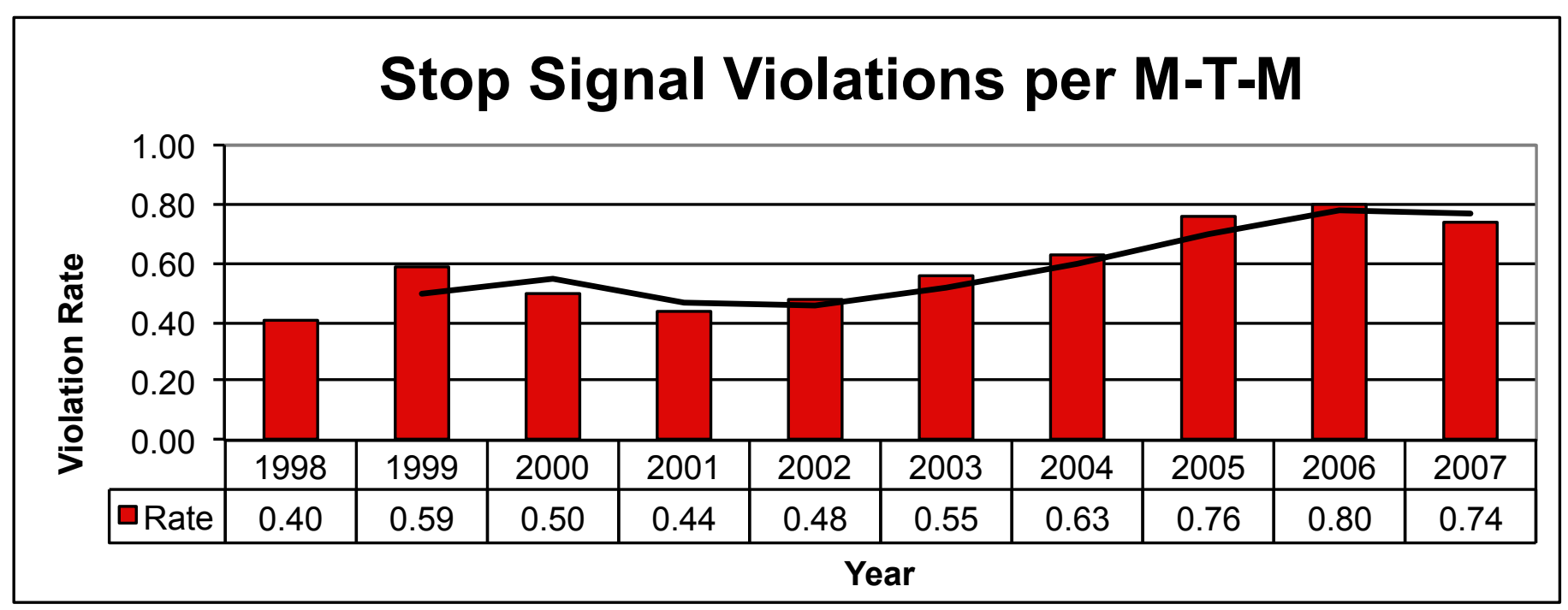

Figure 1. Stop signal violations per million track miles (M-T-M) in US rail operations, 1998-2007. 
Even when violations do not result in an accident, disciplinary action is usually taken against the crew, resulting in the suspension or termination of employment; the implication being that the failure to comply with a rule is the end result of operator negligence. This conclusion, however, begs the question as to why a rail operator, the majority of whom are well trained, experienced and not otherwise impaired, would commit such a gross act of negligence that could result at least in the loss of employment, or at worst, personal injury or even death? Is it possible that there is something else at play in many of these incidents? Human factors systems analyses of rail operations point to multiple equipment, operator, and environmental factors that jointly contribute to safety (Sussman \& Rasslear, 2007). From this perspective, a common set of circumstances are associated with factors that are manifest in operator loss of attentional resources (Parasuraman, 1998; Warm, Parasuraman, \& Matthews, 2008), confirmation bias (Nickerson, 1998), or inattentional blindness (Simons \& Chabris, 1999), with the ultimate result being an error or rule violation, that could, depending on other factors, result in an accident or near miss.

This panel will present an alternative view to the conventional theory of operator negligence as the primary cause of human factors related errors by discussing the role of distraction, mental workload, and attentional errors in commuter rail operations. Distraction during automobile driving has been a topic that has drawn considerable interest among researchers and policy makers, particularly as related to the impact on driving safety of in-vehicle devices such as cellular phones and GPS navigation devices (Lee, 2008; Regan, Lee, \& Young, 2009). However, distraction during rail operations has been less extensively studied. Recent highprofile accidents involving commuter trains in the US, Canada, and Europe have highlighted the need for a better understanding of the role of distraction and attention errors in passenger rail operations.

As Figure 2 indicates, human factors are the leading cause of incidents and accidents in commuter rail operators. Over the period $2002-2011,38 \%$ of all such cases involved human factors. This figure is similar to that reported in other transportation domains, such as commercial aviation. Failures of attention are a leading contributor within the human factors category (Baysari, McIntosh, \& Wilson, 2007). While there has been a slight downward trend in recent years in the overall rates of accidents reported to the Federal Railroad Administration, the proportion of human factors-related accidents continues to be relatively high (see Figure 3).

\section{Total FRA Reportable Accidents/Incidents (Per Million Train Miles)}

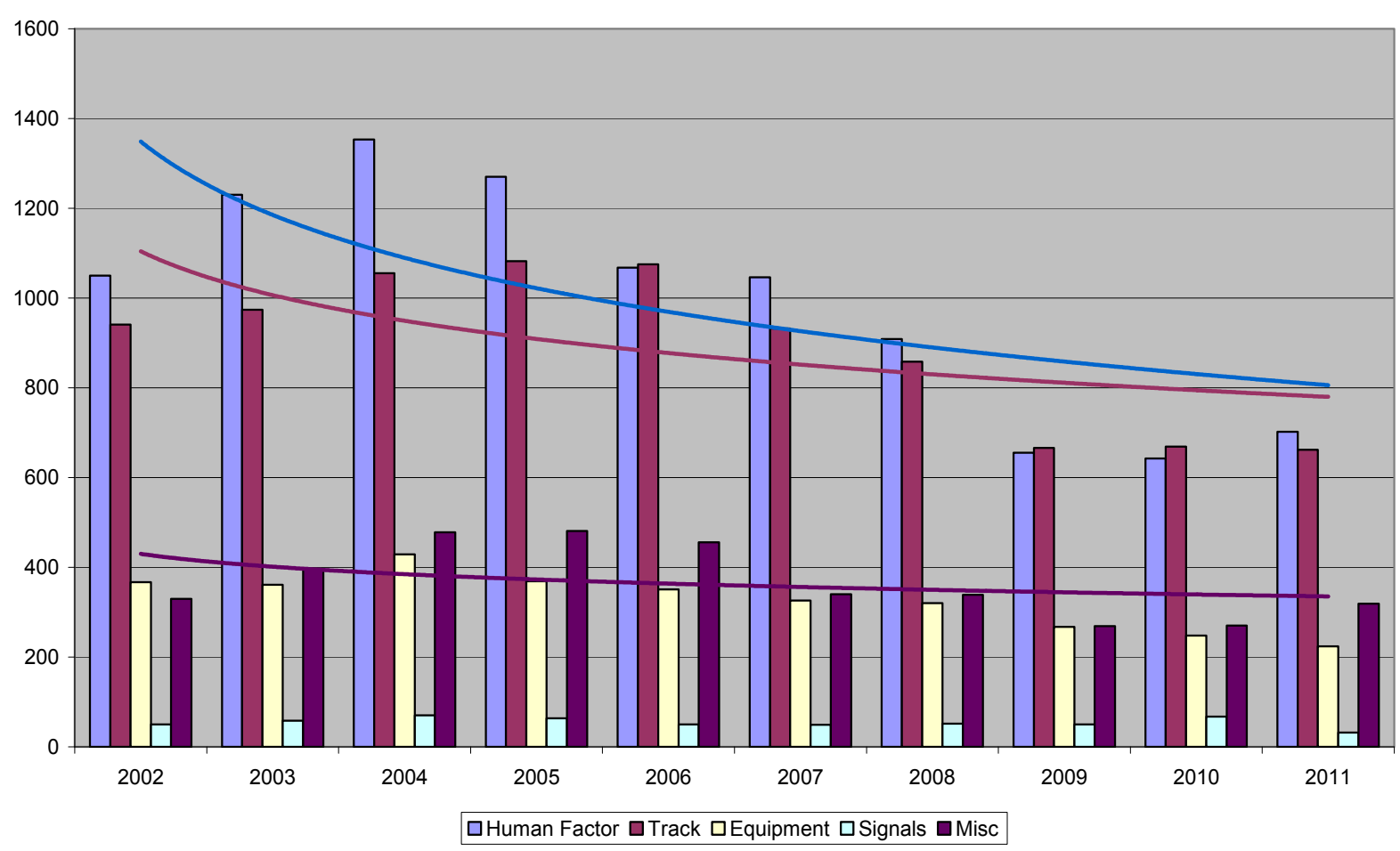

Figure 2. Average proportions of causal factors in accidents and incidents in US rail operations, 2002-2011. 
The four panelists will discuss a number of different approaches to investigate, understand, and mitigate the problem of distraction in rail operations. The panel Chair is Raja Parasuraman, George Mason University. Panel members are George Elsmore, Director of Rail Safety Research and Development at Veolia TransDev Inc., Matthew Isaac, Volpe National Transportation Systems Center, and Donald Fisher, University of Massachusetts, Amherst.

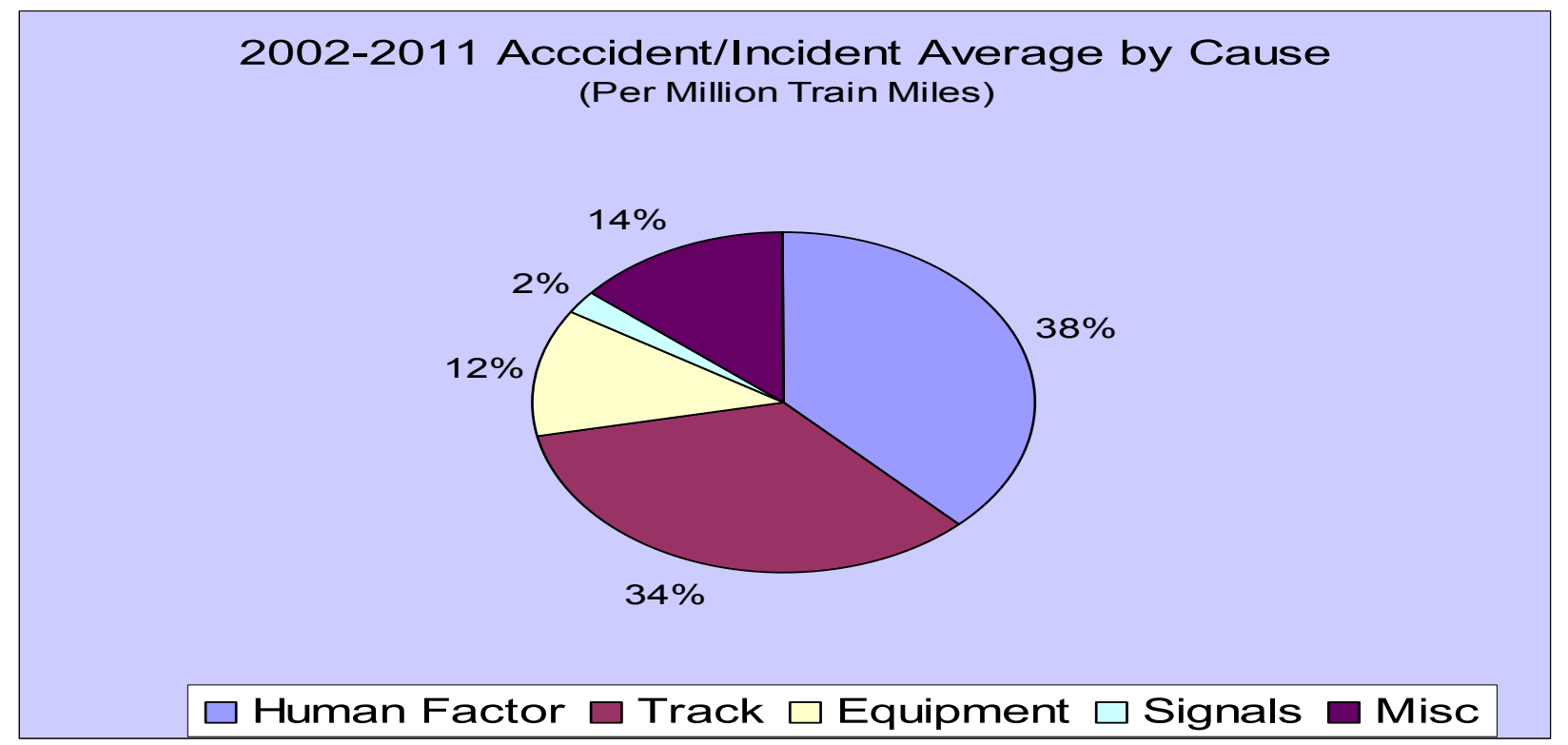

Figure 3. Total reportable Accidents/Incidents in US rail operations, 2002-2011

George Elsmore, will describe the nature of rule violations in commuter rail operations. He will also discuss illustrative accident cases in which distraction was thought to be a contributor factor. Elsmore will discuss Veolia's comprehensive root cause analysis of major rule violations as well as a survey study conducted amongst engineers and conductors. The findings suggested that operator errors were the result of attention lapses, caused in part by the need for sustained attention and excessive mind wandering (i.e., ruminations) on the part of the operators. Referencing data collected by the FRA as well as from internal investigations at Veolia, Elsmore will discuss the role of human factors as the leading cause of rail accidents in the US for the past 10 years, and how Veolia's investigations suggest the number is actually higher than reported. Finally, he will outline a program of research and training aimed at reducing distraction-related rule violations in rail operations. Elsmore is leading Veolia's study of Locomotive engineer distraction, with the partnership and support of the FRA and the Volpe Center for Transportation Studies in Cambridge.

While accident analysis and field studies of locomotive engineers have yielded some insights into the issue of distraction, there is a need for empirical studies of locomotive engineer performance using simulation. In the domain of automobile driving research, numerous simulators are available for empirical studies, from low-cost desktop driving software, through medium-fidelity motion-enabled driving simulators, to high-fidelity full-motion simulators (Fisher, Rizzo, \& Caird, 2010). A similar wide range of simulation facilities is not available in rail operations. Recently, however, the U.S. Department of Transportation's Federal Railroad Administration sponsored the development of a high-fidelity locomotive simulator, the Cab Technology Integration Laboratory (CTIL). The CTIL installed in 2010 at the Volpe National Transportation System Center in Cambridge, MA. Matthew Isaac of the Volpe National Transportation System Center will describe the capabilities of the CTIL, a locomotive simulator that serves as a human factors research laboratory. He will describe how the CTIL provides human factors researchers several capabilities. These include the ability to evaluate new locomotive technologies prior to installation in actual locomotive cabs; prototyping new locomotive-engineer interface and display concepts; and assessing engineer distraction, mental workload, and performance in simulations of diverse operational conditions.

Raja Parasuraman of George Mason University will then briefly describe the results of a two-part study on distraction conducted using the CTIL facility. Experienced locomotive engineers from the Massachusetts Bay Commuter Railroad (MBCR) operated the CTIL simulator over animated track segments while experiencing scenarios differing in task load and potential for inducing distraction. The scenarios involved the simulated operation of a typical MBCR commuter train consisting of 1-SD40 locomotive pulling five coaches operating over the MBCR Providence line from MP 181 (Cranston Yard) to MP 229.7 (South Station), a total distance of 48.7 miles. The method of operation was by a centralized Train Control System (TCS), under the direction of a train dispatcher, supplemented in the field by Automatic 
Block wayside signals. Various performance, subjective, and eye movement measures were obtained from 12 engineers in three different scenarios. Findings from the first study were then used to design a second study aimed at developing a training program for locomotive engineers aimed at educating them on the fundamental concepts of human attention, mind wandering and distraction as well as empowering them with personal sustained attention strategies intended to reduce distraction-related rule violations.

The final panelist will be Donald Fisher, who will serve as Discussant. He will comment on the panel presentations and describe perspectives on distracted driving and their implications for understanding distraction in rail operations and its mitigation.

\section{REFERENCES}

Baysari, M. T., McIntosh, A. S., \& Wilson, J. R. (2007). Understanding the human factors contribution to railway accidents and incidents in Australia. Accident Analysis and Prevention, 40, 1750-1757.

Fisher, D. L., Rizzo, M., \& Caird, J, (2010). Handbook of driving simulation for engineering, medicine, and psychology. Boca Raton, FL: CRC Press.

Lee, J. D. (2008). Fifty years of driving safety research. Human Factors, 50, 521-528.

Nickerson, R. S. (1998). Confirmation bias: A ubiquitous phenomenon in many guises. Reviews of General Psychology, 2, 175-220.

Parasuraman, R. (1998). The attentive brain. Cambridge, MA: MIT Press.

Regan, M. A., Lee, J. D., \& Young, K. L. (2009). (Eds.). Driver distraction: theory, effects, and mitigation. Boca Raton, FL: CRC Press.

Simons, D., \& Chabris, C. F. (1999). Gorillas in our midst: sustained inattentional blindness for dynamic events. Perception, 28, 1059-1074.

Sussman, D. E., \& Rasslear, T. G. (2007). Railroad human factors. Reviews of Human Factors and Ergonomics, 3, 148-189.

Warm, J. S., Parasuraman, R., \& Matthews, G. (2008). Vigilance requires hard mental work and is stressful. Human Factors, 50, 433-441. 